\title{
The Roles of Forgiveness towards Repurchase Intentions from a Cross Cultural Perspective
}

\author{
By Arirat Chueabunkoet Noth* \\ Pensri Jaroenwanit ${ }^{\dagger}$ \\ Rudolph Henry Brown ${ }^{*}$
}

This paper aims to investigate the relationship between forgiveness towards repurchasing intentions from a cross cultural perspective. The study was conducted in the airline industry where customers believed the airline service was not up to expectations. The survey used questionnaires to collect data from Thai and European passengers who had perceived failure of service experienced in the international airline. The result of this study found that Thai and European customers have a different degree of collectivism and forgiveness. Collectivism culture has a positive effect to forgiveness and repurchase intention. Furthermore, customer forgiveness has a positive relationship with the customer's intention to repurchase. More specifically, the study incorporates customer forgiveness as a mediator, thus forgiveness can be influenced by cultural values and can perform the role as a coping strategy by the customer to release negative emotional responses from a service failure and open a gate of opportunity for a customer repurchase intention.

Keywords: Airline, Collectivism culture, Forgiveness, Repurchase intention, Service failure

\section{Introduction}

For more than three decades, marketing scholars have paid attention to customer satisfaction. Most have researchers indicated that satisfaction is strongly related to post purchase behavior intention. Most studies demonstrate that satisfaction can be implied to the customers' memories, the post purchase behavior intention (Anwar and Gulzar 2011, Babin et al. 2005, Kim et al. 2009, Molinari et al. 2008, Oliver 1980, Oliver 1981, Yi and La 2004). A customer will increase repurchase intention when they feel satisfied (Liang 2012).

Notwithstanding, in context of service industries, the characteristics of service such as intangibility, inseparability, heterogeneity and perishability (Berry and Parasuraman 1991, Lovelock and Gummesson 2004, Lovelock and Wirtz 2007) are a hard to control standard. In addition, the service characteristics from customers and providers in the service process cannot disguise the service failures (Boshoff 1997). The service encounter involves

\footnotetext{
* Faculty of Management Science, Khon Kaen University, Thailand.

${ }^{\dagger}$ Associate Professor, Department of Marketing, Faculty of Management Science, Khon Kaen University, Thailand.

$\ddagger$ Professor, Faculty of Management Science, Khon Kaen University, Thailand.
} 
the interpersonal feeling between customers and providers more than exchange (Bove and Johnson 2002). The customers' perception in terms of interaction with the service employees affects the customers' perception toward the company and also influences the customers' satisfaction. Moreover, the degree of interpersonal contact in the service production and the service consumption are influenced by the customers' experiences and attitude. They are important to the service delivery failures and to reach a successful outcome. However, the negative emotion or dissatisfaction may occur when the service delivery does not meet customer expectations or previous experience and also influence the overall degree of satisfaction (Stephens and Gwinner 1998).

The customer who is dissatisfied can be the bridge of a broken relationship between marketers and customers. Most customers seek the opportunity to express their negative emotional feelings. Service failure encourages two negative dimensions through a customer's personality such as revenge and avoidance (McCullough et al. 1997). The way to restore a relationship may offer free gifts or special privileges, and apologize. Moreover, customers can resolve their negative feelings if allowed the opportunity to express their grievances.

The majority of research studies into service failure have focused on the negative emotional effect on a customer complaining, brand switching, (Garcia and Perez 2011, Mattila and Ro 2008, Oliver 1981, Zeelenberg and Pieters 2004), and negative word of mouth. Nevertheless, most researchers have overlooked the positive emotion of coping behavior such as the empathy of forgiveness that can be the bridge to customer satisfaction again and lead the customer to rehabilitate the relationship (Aaker et al. 2004) or have a more favorable repurchase intention. When the negative motivation decreases, customers will be more open minded to increase positive motivation to restore their relationship with the company. Therefore, forgiveness can play a role as a coping strategy for negative behavior owing to poor or bad service (Chung and Beverland 2006, Moschis 2007, Tsarenko and Gobbott 2006, Tsarenko and Tojib 2011, Zourrig et al. 2009). Moreover, forgiveness can lead a customer to repurchase and much more positive action through word of mouth (Howley et al. 2008).

To study consumers' behavior and the consumers' emotion, previous studies indicated that consumer's behavior and consumer's emotion are influenced by culture (Patterson et al. 2006, Triandis 1989, Yoo and Donthu 2002). Customers in different cultures are likely to have different behaviors, different degrees of the service expectation and service engagement (Patterson and Smith 2001). It is likely to be influenced by the individualism-collectivism dimension of their cultural identity. Moreover, few studies of forgiveness indicate that people from collectivist societies may be more forgiving than people in individualist societies.

Unfortunately, post purchase behavior of customers is mostly explained by customer satisfaction while dissatisfaction is considered as being reflected on negative behavior such as complaint, negative word of mouth and brand switching. In fact, some customers repurchase or revisit the firm even when 
they are dissatisfied. Thus this is the challenge and very interesting to examine why some customers continue to repeat purchases despite having the negative emotion or a dissatisfaction of service. This is real happening that marketers should not overlook, especially the academic research should pay more attention to find out more regarding this complex behavior. Besides, the study of customer coping strategies after service failure dissatisfaction at the post purchase stage is a limited study by scholars. Forgiveness is one coping behavior (Tsarenko and Gabbott 2006, Worthington and Schere 2004, Zourrig 2010) it is also a coping strategy after the customers' perception on service failure. This is a way to release negative emotions and minimize any motivation to harm the service provider. Thus, forgiveness not only builds positive behavior to the service provider after service failure, but also provide the basis to restore a relationship between the customer and the firm (Chung and Beverland 2006)

In addition, the study of the relationship between different cultural dimensions such as individualism-collectivism and forgiveness are more interesting to the marketing scholar but most studies have investigated the forgiveness behavior as the dependent variable in the psychology area. Indeed, the relationship of forgiveness could play the role of the mediator between different cultures and repurchase intention.

\section{Literature Review}

This study aims to investigate the relationship between cultural aspects, forgiveness and repurchase intention. The mediating effect of forgiveness is also highlighted in this study. Thus, conceptual framework and hypotheses formulation were based on the existing literature pertaining to the culture of collectivism, forgiveness and repurchase intension as follows.

\section{Individualism (IV) - Collectivism (CV)}

The last 35 years, many scholars have worked on the individualismcollectivism dimension and they found worthwhile benefits of this dimension. The perception and behavior of people in the collectivist culture are different from individualist culture, Individualism-collectivism has been has been hypothesized as conditions that encapsulate views, attitudes, customs, roles, ideals, and actions in different cultures (Hofstede 2001, Hofstede et al. 2010, Triandis 2004)

According to Hofstede (2001) many Asian countries demonstrate collectivism culture. Asians place the uppermost importance on social harmony, cooperation, shared responsibility, role compliance, conformity to the group, courtesy, tolerance, and moral discipline. Thailand is very much a collectivist nation; this manifests itself in an intima teen during pledge to the group members and fidelity in-group. Any wrongdoing points to loss face and Thai nationals are to some extent delicate in disposition; they abhor being humbled in front of others. While, the individualism culture is demonstrable in Western countries (Meng 2010), such as the United Kingdom and many 
European countries that are highly individualistic. The route to happiness is through personal fulfillment, self-actualization (Hofstede Center n.d.). Based on the discussion, this study proposes a hypothesis relationship amongst nationality and collectivism cultures.

\section{$H_{1}$ : Thai and European Passengers are Different Degree of Collectivism Culture}

At present, the interest in cross culture investigation on interpersonal relationships is increasing in consumer behavior studies, especially the adaptation of cross culture psychology has expanded theories in cultural differences (Recine et al. 2007, Triandis 2004, Zourrig et al. 2009). Cultural difference dimensions such as individualism-collectivism may influence human personality. In the case of interpersonal conflict, the perceived group membership of the offender may influence the disposition of an offended party toward engaging in coping behavior such as forgiveness (Zourrig 2010). Based on the discussion, this study proposes a hypothesis, a relationship among nationality and forgiveness.

\section{$\mathrm{H}_{2}$ : The Passengers from Collectivist and Individualist Culture Have Different Degrees of Forgiveness}

The study of the relationship between individualism-collectivism and forgiveness as a coping behavior within a stressful event found individualismcollectivism influenced customer forgiveness. Collectivist people are more likely to have forgiveness than individualist (Neto and Mullet 2004, Takaku et al. 2001, Zourrig et al. 2009) because of collectivist culture placing a high value on the interdependence and empathy (Feigenblatt 2010). Benevolence and good will maintain relationships (Zourrig et al. 2009). Conversely, the people from individualistic culture are likely to have the motivation of negative behaviors such as revenge (Tsarenko and Tojib 2011). In addition, individualist customers have a lower intention to praise service providers even if they perceive positive service quality; meanwhile, collectivist customers are more likely to make use of a service delivery via word of mouth referral in the purchase of services (Liu et al. 2001). Based on the discussion, this study proposes a set of hypothesis of the following:

$H_{3}$ : Collectivism Culture has a Positive Effect in Forgiveness

$\mathrm{H}_{4}$ : Collectivism Culture has a Positive Effect in a Repurchasing Intention

\section{Repurchase-Intention (RI)}

Repurchase intention in reference to the intended behavior, can have positive or negative intention to repeat purchase (Oliver 1999). Two kinds of positive repurchase intent are: intent to re-buy and commitment to assume positive word of mouth and recommendation (Zeithaml and Bitner 1996). Repurchase intent and positive word of mouth are together a favorable 
behavioral intention that is more likely to befall when clients are satisfied. Conversely, brand-switching, negative word of mouth and complaining are divergent behavioral intentions that are more probable to transpire when clienteles are dissatisfied, especially in the case of service failure (Liu et al. 2001).

However, since service failures occur, most of the firm usually recovered their service. It involves attempts to restore the interpersonal relationship. Chung and Beverland (2006) indicated that forgiveness involved a renegotiation of the relationship between marketer and consumer, such as repatronage, repurchase intention and positive word of mouth (Levesque and McDougall 2000, Palmer et al. 2000) consumers are also willing to continue to engage their relationship with the marketer after perceived service recovery. Based on the discussion, this study proposes a hypothesis relationship among forgiveness and repurchase intention.

\section{$H_{5}$ : Forgiveness has a Positive Effect in Consumers Repurchase Intention}

\section{A Potential Mediator of Forgiveness (FG)}

Forgiveness is defined as rescinding resentment against or the desire to chastise; to discontinue being irritated by, to forgive or to cease all claim to castigate or exact consequence (an offense) (McCullough et al. 2006). To understand the role of forgiveness as coping strategies that can be used to conduct how forgiveness can affect coping behaviors. Zourrig et al. (2009) and Tsarenko and Gabbott (2006) adapted the cognitive appraisal theory of Lazarus and Folkman (1984) to advance an intellectual emotive coping model which describes how patron forgiveness might role as a coping process leading to renovating the interpersonal relationship.

The concept of forgiveness has been researched and discussed in disciplines such as management and various divisions of psychology including social behavior (Chung and Beverland 2006). Several concepts of forgiveness are closely related to marketing and value to marketers (Aaker et al. 2004). When people forgive, they resist or reduce the motivation to anger or seek revenge (Zourrig et al. 2009). The customer are likely to dispense with negative emotions and change to a positive emotion such as empathy, compassion and sympathy, this leads to forgiveness coping (Worthington and Scherer 2004, Zourrig et al. 2009). Thus, Forgiveness may build positive emotional reaction to a service failure or a service provider and provides a chance to restore the relationship or minimize bad feelings and harm (Chung and Beverland 2006).

At present, the adaptation of cross culture psychology has been expanding theories in relation to cultural differences such as the study of Recine et al. (2007), Triandis (2004). Cultural difference dimensions such as individualismcollectivism may influence consumer behavior such as emotion and forgiveness in different directions (Zourrig et al. 2009). When the forgiveness works within an individual in a service context, customers will gradually reduce negative emotions such as anger and vengeful tend will decrease until it 
disappears. Negative motivation is harmful to the offending firm, while positive emotion, such as empathy, sympathy and benevolence tend to increase, the motivation to continue the relationship with the transgressor and a willingness to interact with the company again (Howley et al. 2008).

Hence, forgiveness can indicate a future intention to a repeat purchase intention and positive word of mouth behaviors. In contrast, unforgiveness can be represented by switching to another provider and negative word of-mouth behavior (Chung and Beverland 2006). However forgiveness displays the potential to hasten the restoration of a stressed relationship between a service provider and a client. Moreover, even some customer's reluctance to forgive may not restore the relationship to the same level as the original quality, but augment the relationship quality of the commercial affiliation and embolden positive word of mouth (Enright et al. 1992). Based on the discussion, this study proposes a hypothesis relationship between collectivism culture and forgiveness. It is expected that forgiveness will mediate the influence of culture different and repurchase intention, reflecting the mechanism underlying consumer's decision making in the context of international airline service.

\section{$H_{6}$ : Forgiveness in Service Failure Significantly Mediates the Influence of Collectivism Culture on Repurchasing Intention}

\section{Methods}

\section{Samples and Procedure}

This study is a pilot study that adapted the forgiveness theory, collectivism culture and post purchase of customer behavior. The sampling technique is based on two stage sampling approaches. The first stage is convenience sampling. The second is purposive sampling which is used for screening passenger, who have been dissatisfied with their experience of service with an international airline. Next, they were requested to complete the measures of collectivism culture, forgiveness and repurchase intention survey. The survey was data collected from 250 international airline passengers: 115 Thai nationals and 135 Europeans.

\section{Measures}

The research participants were instructed to indicate the degree to which they agree or disagree with each of the scale items in the Likert type (1=strongly disagree, $7=$ strongly agree). Repurchase intention adapted from Maxham III (2001) and Anderson and Srinivasan (2003) consists of 6-item scale, reliability 0.609 . The collectivism culture measure was adapted from CVSCALE by Yoo et al. (2011) contains 6-items, reliability 0.889 . Forgiveness measure was adapted from the TRIM-18 by McCullough et al. (2006) contains 18 -items, reliability 0.906. 


\section{Results}

\section{Descriptive Result}

The profile of the research participants is: 115 Thai passengers and 135 European passengers, male $(61.2 \%)$, age between $35-44$ years old $(41.2 \%)$, Master degree holders (35.6\%), and travelling by plane between 11-20 times in the past 2 years $(35.2 \%)$. The experiences of service failure experienced by passengers included flight delays $(26.1 \%)$ and baggage mishandling (18.9\%): both of which led to passenger dissatisfaction with service. When service failure occurs the airline likes to compensate by means of apology and the offering of free food and beverage.

According to Table 1 Thai passengers exhibit high forgiveness and repurchase intention congruent with a collectivist culture; all of which strongly imply that Thais indeed form a collectivist culture. Simultaneously, European passengers demonstrate a low level of forgiveness, repurchase intention and few tenets found in a collectivist culture; there implies Europeans are in fact individualist in their makeup. An interpretation of the results determined by comparison between mean and median score is seen below.

Table 1. Descriptive Statistic and Reliability

\begin{tabular}{|l|c|c|c|c|c|c|c|}
\hline \multirow{2}{*}{} & \multicolumn{3}{|c|}{$\begin{array}{c}\text { Thai Passengers } \\
(\mathbf{n = 1 1 5})\end{array}$} & \multicolumn{3}{c|}{$\begin{array}{c}\text { European Passengers } \\
(\mathbf{n = 1 3 5})\end{array}$} & \multirow{2}{*}{ Median } \\
\cline { 2 - 8 } & Mean & SD. & & Mean & SD. & & \\
\hline Collectivism & 5.577 & 0.946 & High & 2.957 & 0.985 & Low & 3.833 \\
\hline Forgiveness & 5.152 & 0.921 & High & 2.845 & 0.942 & Low & 4.083 \\
\hline $\begin{array}{l}\text { Repurchase } \\
\text { Intention }\end{array}$ & 4.489 & 0.855 & High & 2.477 & 0.867 & Low & 4.000 \\
\hline
\end{tabular}

Source: Fieldwork survey data 2014.

Hypothesis Testing

\section{$H_{1}$ : Thai and European Passengers are Different in Degrees of Collectivism Culture \\ $\mathrm{H}_{2}$ : Passenger from Collectivist and Individualist Culture are Different in Degrees of Forgiveness}

To test this set of hypotheses, independent sample $t$-tests were conducted for the collectivism culture and forgiveness score. The result of testing shows Thai and European passengers have significantly different degrees of collectivist culture in their composition. According to results in Table 1 it is indicated that Thai passengers are from a collectivist culture, while Europeans belong to an individualist culture. Hence, the tests of two hypotheses were as per the following; passengers from a collectivist culture and an individualist culture demonstrate significantly dissimilar degrees of forgiveness and repurchase intention. Therefore $\mathrm{H}_{1}$ and $\mathrm{H}_{2}$ are supported (Table 2). 
Vol. 1, No. 3 Noth et al.: The Roles of Forgiveness towards Repurchase Intentions...

Table 2. The Results of Independent Sample t-test of Hypotheses: $\mathrm{H}_{1}$ and $\mathrm{H}_{2}$

\begin{tabular}{|l|c|c|c|}
\hline Test of hypotheses $(\mathbf{n}=\mathbf{2 5 0})$ & $\boldsymbol{t}$ & $\boldsymbol{p}<\mathbf{0 . 0 0 1}$ & Meaning \\
\hline Collectivism $\left(\mathbf{H}_{\mathbf{1}}\right)$ & -23.989 & 0.000 & Supported \\
\hline Forgiveness $\left(\mathbf{H}_{2}\right)$ & -7.744 & 0.000 & Supported \\
\hline Repurchase Intention & -9.566 & 0.000 & Supported \\
\hline
\end{tabular}

Source: Fieldwork survey data 2014.

$H_{3}$ : Collectivism Culture has a Positive Effect to a Repurchasing Intention

$\mathrm{H}_{4}$ : Collectivism Culture has a Significant Positive Effect on Forgiveness

$H_{5}$ : Forgiveness has a Significant Positive Effect on Repurchasing Intention

Regression was conducted to test hypotheses $\mathrm{H}_{3}, \mathrm{H}_{4}$, and $\mathrm{H}_{5}$. The results show (Table 3 and Figure 1) that a collectivist culture produces a significantly positive effect on a repurchase intention $\left(\mathrm{R}^{2}=0.440, \beta_{\mathrm{H} 3}=0.699, t=13.947\right.$, $p<0.001)$. The causal relationship between a collectivist culture and forgiveness $\left(\mathrm{H}_{4}\right)$ was found to be positively significant $\left(\mathrm{R}^{2}=0.313, \beta_{\mathrm{H} 4}=0.750\right.$, $t=10.635, p<0.001)$. Therefore, $\mathrm{H}_{3}$ and $\mathrm{H}_{4}$ are supported. What's more, through the course of hypotheses testing of the relationship between forgiveness and repurchase intention $\left(\mathrm{H}_{5}\right)$ it was revealed that forgiveness has a strong positive relationship with repurchase intention $\left(\mathrm{R}^{2}=0.286, \beta_{\mathrm{H} 5}=0.423, t=10.044\right.$, $p<0.001)$. Consequently, $\mathrm{H}_{5}$ is supported.

\section{$H_{6}:$ Forgiveness in Service Failure Significantly Mediates the Influence of Collectivism Culture on Repurchasing Intentions}

The Sobel statistical method (Sobel 1982) was applied to test the mediating effect in hypotheses $\mathrm{H}_{6}$. The results are shown as indicated by Table 3 and Figure 1 in that the mediating role of forgiveness has an effect on the relationship between collectivism and the intent to repurchase $\left(\beta_{\mathrm{H} 6}=0.551 ; \mathrm{z}\right.$ test $=10.582 ; \mathrm{p}<0.001)$. So, $\mathrm{H}_{6}$ is supported.

Table 3. The Results Regression of Hypotheses Testing: $\mathrm{H}_{3}, \mathrm{H}_{4}, \mathrm{H}_{5}$ and $\mathrm{H}_{6}$

\begin{tabular}{|c|c|c|c|}
\hline Hypothesis & $\begin{array}{c}\text { Independent } \\
\text { variable }\end{array}$ & $\begin{array}{c}\text { Dependent } \\
\text { variable }\end{array}$ & $\beta$ coefficient, $t, p$ of $I V$ \\
\hline $\mathbf{H}_{3}$ & Collectivism & $\begin{array}{c}\text { Repurchase } \\
\text { intention }\end{array}$ & $\begin{array}{c}\beta_{\mathrm{H} 3}=0.699 * * * ; t=13.947 ; \\
\text { SE. }=0.044 ; \mathrm{Sig}=0.000\end{array}$ \\
\hline $\mathbf{H}_{4}$ & Collectivism & Forgiveness & $\begin{array}{c}\beta_{\mathrm{H} 4}=0.750 * * * ; t=10.635 ; \\
\text { SE. }=0.048 ; \text { Sig }=0.000\end{array}$ \\
\hline $\mathbf{H}_{5}$ & Forgiveness & $\begin{array}{c}\text { Repurchase } \\
\text { intention }\end{array}$ & $\begin{array}{c}\beta_{\mathrm{H} 5}=0.423^{* * *} ; t=10.044 ; \\
\text { SE. }=0.051 ; \operatorname{Sig}=0.000\end{array}$ \\
\hline $\mathbf{H}_{6}$ & $\begin{array}{l}\text { Collectivism } \\
\text { Forgiveness }\end{array}$ & $\begin{array}{l}\text { Repurchase } \\
\text { intention }\end{array}$ & $\begin{array}{c}\beta_{\mathrm{H} 6}=0.552 * * *(\mathrm{a}=0.766 \times \mathrm{b}=0.721) ; \\
\mathrm{SE}_{\mathrm{a}}=0.048 ; \mathrm{SE} \mathrm{b}_{\mathrm{b}}=0.051 \\
\text { z-test }=10.582 ; \mathrm{Sig}=0.000\end{array}$ \\
\hline
\end{tabular}

Source: Fieldwork survey data 2014

Note: Sobel test (Sobel 1982) using for test the mediation effect, as provided: $\mathbf{z}=\mathrm{ab} / \mathrm{SE}$ ab, while $\mathbf{S E}_{\mathbf{a b}}=\sqrt{b^{2} S E a^{2}+a^{2} S E b^{2}}$. Where $\mathbf{a}$ and $\mathbf{b}$ are the regression coefficient for the relationship between the independent (a), dependent (b) and mediator variables; $\mathbf{S E}_{\mathbf{a}}$ and $\mathbf{S E}_{\mathbf{b}}$ are the standard error of the relationship between the independent, dependent variables and the mediator variables. 
Figure 1. The Roles of Forgiveness Mediation Model

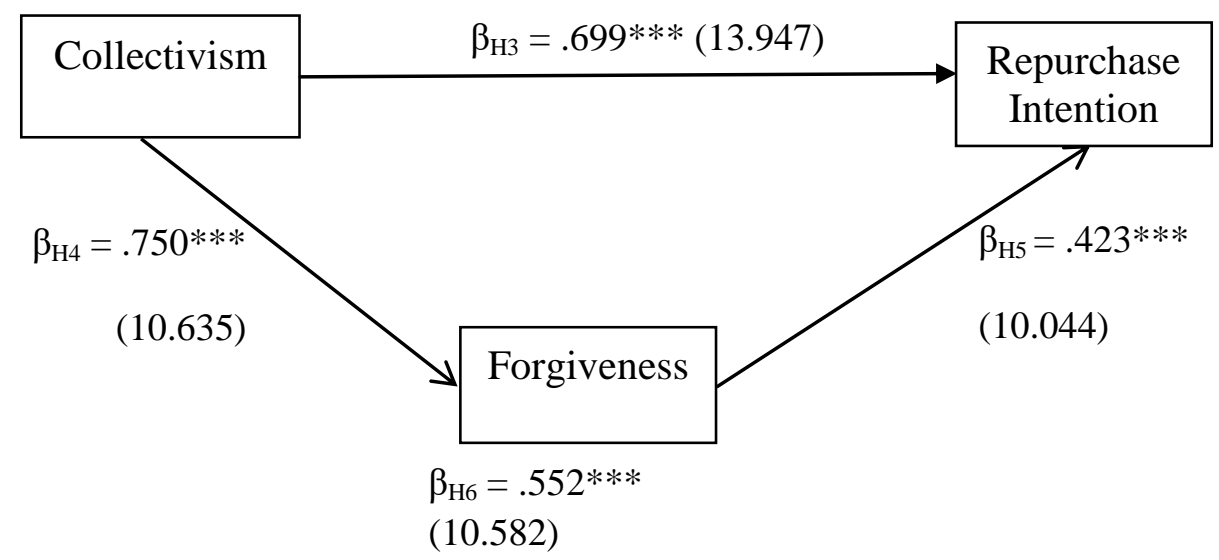

Source: Fieldwork survey data 2014.

\section{Discussion}

According to the findings of this study, the result of service failure will lead to customer dissatisfaction; accordingly, this can be good reason for broken relationships between airline service providers and their customers. However, the positive emotions will occur when a customer seeks the way out from negative emotions such as using the coping mechanism of forgiveness (McCullough et al. 1997). When negative emotions decrease, customers will be more open minded and alter behavior to empathy to restore their relationship with the firm and re-establish customer repurchase from the same service provider in the future (Chung and Beverland 2006, Zourrig et al. 2009). This behavior refers to the mechanism of the forgiveness role as a customer coping strategy arising from dissatisfaction or disappointment (Tsarenko and Gabbott 2006, Worthington and Schere 2004). Moreover, the culture value as collectivism is influence forgiveness as well (Zourrig et al. 2009).

The results of this study found that Thai and European passengers have a different degree of collectivism culture (Yoo and Donthu 2002) and also a different degree of forgiveness (Zourrig et al. 2009). Moreover Collectivism culture has a positive influence the repurchase intention and forgiveness while forgiveness has a positive influence repurchase intention (Howley et al. 2008). This implies that the role of forgiveness is a mediator in the relationship between collectivism cultures and repurchase intention has been confirmed in this study. As coping strategies, customers tend to release their negative emotions and transform their emotions by expressing benevolence and empathy change to be happiness. There is an interpretation that forgiveness can transform negative emotions to positive emotional reactions, there is the bridge to restore the relationship between customer and service provider. Thus, the conclusion of this relationship can be indicated by renegotiation, re-patronage, an intention to repurchase, and positive word of mouth through forgiveness which is used as a customer coping behavior. 
The benefit of this study was to extend knowledge of the customer purchasing behavior after dissatisfaction at the repurchase with the positive coping strategy. Moreover, setting the foundation for studying the relationship between collectivism culture, customer forgiveness and repurchase intention which results in new academic knowledge and encourages researchers to use this knowledge in the future. For the managerial benefit, marketers can apply the result of this study on planning the service recovery strategies to reduce customer negative emotion and to encourage them to continue purchasing and to retain loyalty because customer forgiveness can create the opportunity to the marketer to recover the emotion from prior to the service failure. In addition, managers can evaluate disadvantages after the service failure and avoid future mistakes with customers, particularly with service encounters directly between the service employee and customers. It is vitally important to understand the utmost importance of service transgressions and service failure because the cost to establish new customers are vastly more expensive than maintaining existing customers (Liang 2012). Especially in high-contact services such as the airline industry. However, this study conduct only one dimension of by Hofstede (2001). Other dimensions, such as masculinity, power distance, uncertainty avoidance, and long-term orientation may also have an influence on forgiveness. Moreover, this study did not compare mediating effect of forgiveness between Thai and European. There is the limitation of this study, thus future research may conduct with another factor and comparison mediating effect as abovementioned.

\section{Acknowledgements}

This study belongs to the partial of dissertation of a doctoral program in business administration, Khon Kaen University. Meanwhile, the main study encompasses the topic of the critical roles of forgiveness toward post purchase behavior among cross cultural airline passengers under the supervision of Associate Professor Dr. Pensri Jaroenwanit and Professor Dr. Rudolph Henry Brown.

\section{References}

Aaker J, Fournier S, Brasel AS (2004) When good brands do bad. Journal of Consumer Research 31(June): 1-16.

Anderson EW, Srinivasan SS (2003) E-satisfaction and E-loyalty: a contingency framework. Psychology and Marketing 20(2): 123-138.

Anwar S, Gulzar A (2011) Impact of perceived value on ward of mouth endorsement and customer satisfaction: Mediating role of repurchase intentions. International Journal of Economics and Management Sciences 1(5): 46-54.

Babin BJ, Lee YK, Kim EJ, Griffin M (2005) Modeling consumer satisfaction and word of mouth: restaurant patronage in Korea. Journal of Service Marketing 19(3): 133-139. 
Berry LL, Parasuraman A (1991) Service marketing: Competing through Quality. New York: The Free Press.

Boshoff C (1997) An experimental study of service recovery option. International Journal of Service Industry Management 8(2): 110-130.

Bove LL, Johnson LW (2002) Predicting personal loyalty to a service provider. Australian Marketing Journal 10(1): 24-35.

Chung E, Beverland M (2006) An exploration of consumer forgiveness following marketer transgression. Advance in Consumer Research 33: 98-99.

Enright RD, Gassin E, Wu CR (1992) Forgiveness: a developmental view. Journal of Moral Education 21(2): 99-114.

Feigenblatt OF (2010). Forgiveness and culture: An interdisciplinary dialogue. Journal of History and Social Sciences 1(1): 1-9. Available from: http://bit.ly/1KwsCH1.

Garcia IS, Perez RC (2011) Effects of dissatisfaction in tourist services: The role of anger and regret. Tourism Management 32: 1397-1406.

Hofstede G (2001) Culture's consequences $\left(2^{\text {nd }}\right.$ ed.). Thousand Oaks: Sage Publications.

Hofstede Center (n.d.) Cultural Tools: Country Comparison. Available from: http://www.greet-hofstede.com. [Accessed: 7 October 2013].

Hofstede G, Hofstede GJ, Minkov M (2010) Cultures and Organizations-Software of the Mind. New York: McGraw Hill.

Howley MJ, Ward JC, Brown SW (2008) The Forgiveness Processes of Very Dissatisfied Customers. Available from: from http://bit.ly/1IquBxt or http://bit.ly/ 1GJVHQU. [Accessed: 20 August 2013]

Kim TT, Kim WG, Kim HB (2009) The effect of perceived justice on recovery satisfaction, trust, word-of-mouth, and revisit intention in upscale hotels. Tourism Management 30: 51-62.

Liu BS, Furrer O, Sudharshan D (2001) The relationships between culture and behavioral intentions toward Services. Journal of Service Research 4(2): 118129.

Lazarus RS, Folkman S (1984) Stress, Appraisal, and Coping. New York: Springer Publishing.

Levesque TJ, McDougall GHG (2000) Service problems and recovery strategies: An experiment. Canadian Journal of Administrative Sciences 17(1): 20-37.

Liang YH (2012) Effect of personality on satisfaction and repurchase intention of online games. Proceedings of the 2012 IEEE ICMIT. 348-352.

Lovelock C, Gummesson E (2004) Whither service marketing?: In search of a new paradigm and fresh perspectives. Journal of Service Research 7(1): 20-41.

Lovelock C, Wirtz L (2007) Services Marketing: People, Technology, Strategy (6 $^{\text {th }}$ ed.). USA: Prentice Hall.

Mattila AS, Ro H (2008) Discrete negative emotions and customer dissatisfaction response in a casual restaurant setting. Journal of Hospitality and Tourism Research. 32(1): 89-107.

Maxham III. JG (2001) Service recovery's influence on consumer satisfaction, positive word of mouth, and purchase intentions. Journal of Business Research 54:11-24.

McCullough ME, Worthington EL, Rachal KC (1997) Interpersonal forgiving in close Relationship. Journal of Personality and Social Psychology 73: 321-336.

McCullough ME, Root LM, Cohen AD (2006). Writing about the benefits of an interpersonal transgression facilitates forgiveness. Journal of Consulting and Clinical Psychology 74(5): 887-897. 
Vol. 1, No. 3 Noth et al.: The Roles of Forgiveness towards Repurchase Intentions...

Meng F (2010) Individualism/collectivism and group travel behavior: a cross cultural perspective. International Journal of Culture, Tourism and Hospitality Research 4(4): 340-350.

Molinari LK, Abratt R, Dion P (2008) Satisfaction, quality and value and effects on repurchase and positive word-of-mouth behavioral intentions in a B2B services context. Journal of Service Marketing (22)5: 363-373.

Moschis GP (2007) Stress and consumer behavior. Journal of the Academy of Marketing Science 35(3): 430-444.

Neto F, Mullet E (2004) Personality, self-esteem, and self-construal as correlates of forgivingness. European Journal of Personality 18(1): 15-30.

Oliver RL (1980) A cognitive model of the antecedents and consequences of satisfaction decisions. Journal of Marketing Research 17(November): 460-469.

Oliver RL (1981) Measurement and evaluation of satisfaction process in retail settings. Journal of Retailing 57(3): 25-48.

Oliver RL (1999) Whence consumer loyalty? Journal of Marketing 63(special issue): 34-38.

Palmer A, Beggs R, Keown-McMullan C (2000) Equity and repurchase intention following service failure. Journal of Service Marketing 14(6): 513-528.

Patterson PG, Cowley E, Prasongsukarn K (2006) Service failure recovery: The moderating impact of individual-level cultural value orientation on perceptions of justice. International Journal of Research in Marketing 23: 263-277.

Patterson PG, Smith T (2001) Relationship benefits in service industries: A replication in southeast Asian context. Journal of Service Marketing 1: 6-7, 425-443.

Recine AG, Werner JS, Recine L (2007) Concept analysis of forgiveness with a multi-cultural emphasis. Journal Compilation 308-316.

Sobel ME (1982) Asymptotic confidence intervals for indirect effect in structural equation models. Sociological Methodology 13: 290-312.

Stephens N, Gwinner KP (1998) Why do not some people complain? A cognitiveemotive process model of consumer complaint behavior. Journal of the Academy of Marketing Science 26(summer): 172-189.

Takaku S, Weiner B, Ohbuchi KI (2001) A cross-cultural examination of the effects of apology and perspective taking on forgiveness. Journal of Language and Social Psychology 96(20): 144-166.

Triandis HC (1989) The self and social behavior in different cultural contexts. Psychology Review 96: 269-289.

Triandis HC (2004) The many dimension of culture. Academic of Management Executive 18(1): 88-93.

Tsarenko Y, Gabbott M (2006) Forgiveness: A New Insight in Business Relationships. American Marketing Association: 4-7.

Tsarenko Y, Tojib DR (2011) A transactional model of forgiveness in the service failure context: a customer-driven approach. Journal of Service Marketing 25(5): 381-392.

Worthington EL Jr, Scherer M (2004) Forgiveness in an emotion-focused coping strategy that can reduce health risks and promote health resilience: Theory, review and hypotheses. Psychology and Health 19: 385-405.

Yi Y, La S (2004) What influences the relationship between customer satisfaction and repurchase intention?: Investigating the effects of adjusted expectations and customer loyalty. Psychology and Marketing 21(5): 351-373.

Yoo B, Donthu N (2002) The effects of marketing education and individualism cultural values on marketing ethics of students. Journal of Marketing Education 24(2): 92-103. 
Yoo B, Donthu N, Lenartowicz T (2011) Measuring Hofstede's five dimensions of cultural values at the individual level: Development and validation of CVSCALE. Journal of International Consumer Marketing 23: 193-210.

Zeelenberg M, Pieters R (2004) Beyond valence in customer dissatisfaction: a review and new findings on behavioral responses to regret and disappointment in failed services. Journal of Business Research: 57(4) 445-455.

Zeithaml VA, Bitner MJ (1996) Service Marketing. New York: McGraw Hill.

Zourrig H, Chebat JC, Toffoli R (2009) Exploring cultural differences in customer forgiveness Behavior. Journal of Service Management 2(4): 404-418.

Zourrig H (2010) In-Group Love and Out-Group Hate? A Cross Cultural Study on Customers' Revenge, Avoidance and Forgiveness Behaviors Following Interpersonal Conflicts in Service Encounters. AMS Conference. American Society of Business and Behavioral Sciences (ASBBS). 
